\title{
Analysis of Smart Zone Heating in Different Heating Systems
}

\author{
Rastislav Ingeli ${ }^{1 *}$, Peter Buday ${ }^{1}$ \\ ${ }^{1}$ Department of Building Structures, Faculty of Civil Engineering, Slovak University of Technology, 81005 Bratislava, \\ Radlinského 11, Slovak Republic \\ * Corresponding author, e-mail: ingeli@ehb.sk
}

Received: 02 November 2020, Accepted: 21 May 2021, Published online: 17 September 2021

\begin{abstract}
The basic concept in the design of buildings with zero energy consumption is, in addition to high-quality thermal properties of the building envelope, also a correct and efficient system of heating and hot water preparation in residential buildings. One of the basic concepts when designing heating systems is a zone heating system. It is a system that brings effective regulation according to heating zones. In practice, the question sometimes arises as to whether zone regulation of individual rooms in small family houses is necessary. That is whether in such buildings, zone heating is not an unnecessary investment cost. In this paper, we analyze the effect of zone heating in two types of heat transfer systems on the internal operating temperature in the individual analyzed zones, which are interconnected by an internal partition structure. It is a verification that even in smaller spaces, zone heating has a significant potential for energy savings.
\end{abstract} Keywords

zone heating, smart control, COVID-19, operating temperature, energy performance of building

\section{Introduction}

Act no. 300/2012 Coll. [1] stipulates that from 01 January 2021 buildings with almost zero consumption will have to be designed $[2,3]$. A building with almost zero consumption is classified in terms of energy efficiency of buildings in energy class A0 for the global indicator, which is primary energy. To achieve this category of buildings, it is necessary to improve the building envelope from a thermal-technical point of view and to find the optimal solution that ensures a balance between the costs of progressive materials, technical equipment of buildings and the overall reduction of energy consumption. One of the factors is the configuration of the building envelope on which the energy savings depend. Except of the thermal technical properties of the building envelope, which is part of the thermal protection of buildings, the selected heat source for heating and hot water also has a significant impact on the energy class of residential buildings. In this report, we analyze, in a selected residential room, the impact of the heating transfer system on zone heating, which is one of the basic concepts for buildings with almost zero energy consumption. In the analysis, we combine different types of heat transfer to the space and monitor their impact on air temperature and operating temperature in individual zones that interact with each other. One zone is realized with a heat source and the other zone without.

\subsection{Smart zone heating}

One of the advantages of intelligent heating is zone heating. Fig. 1 shows the intelligent heating scheme. It is a CPUS system. System CPUS records the real-time temperature flow for each zone (Fig. 2). System CPUS records the real-time temperature flow for exterior (Fig. 2). Temperatures (interior, exterior) are recorded in the CPUS monitoring application.

The application is online and is available via the internet. The whole building is controlled by heating by adjusting the internal temperature of each zone. Zones are the rooms in the building.

Intelligent systems have a future in the construction industry. This is touchless driving, which is very advantageous in the current time of the COVID-19 pandemic. It is not just intelligent heating but also comprehensive intelligent building control. Control heating, lighting, cooling, ventilation, and other equipment. Since the 1980s, smart buildings have aroused the interest of researchers. This continuous evolution has led to the more frequent use of the expression "smart buildings". Although this term has evolved since the 1980s, there is still no consensus on how to define the intelligence of a building [4]. The concept of smart buildings has received several definitions and interpretations. Several researchers [5-8] have emphasized the term intelligent building, while others [9-12] have emphasized the term smart building. In addition to intelligent 


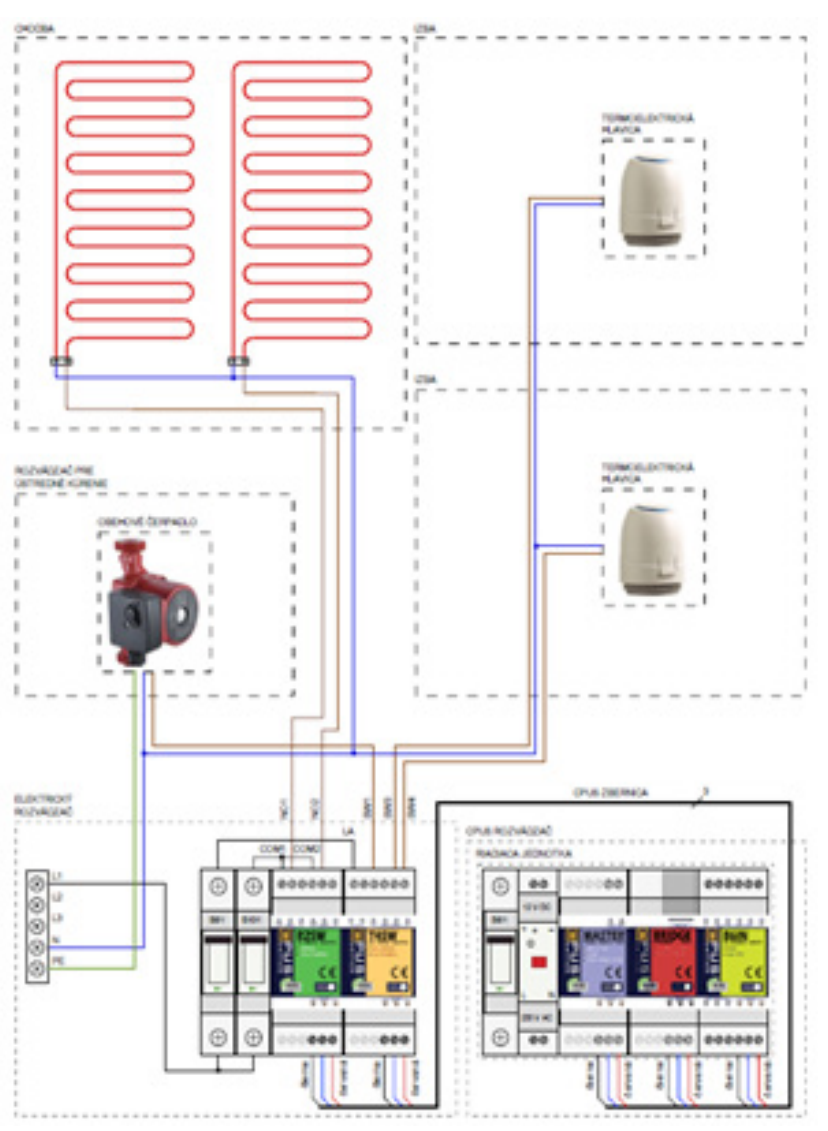

Fig. 1 Diagram of the heating system in the apartment - control system CPUS
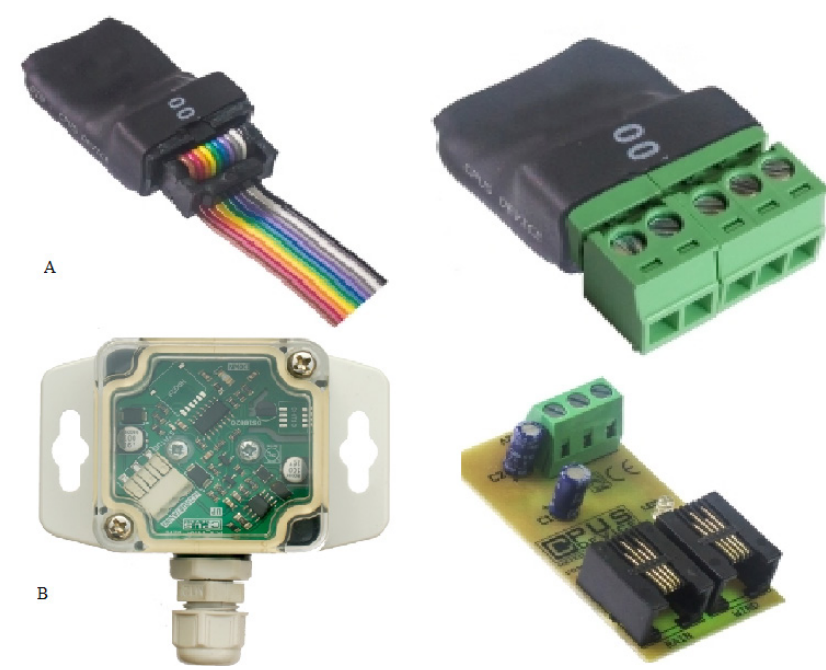

Fig. 2 Temperature sensors; A - Internal temperature sensor; B - External temperature sensor - Weather station

building comes to the fore the concept of smart cities. The concepts "smart city" and "smart building" emerged in the 1980s [13] and evolved similarly.

\subsection{Heating systems}

Thermal performance of building envelopes has noticeably improved during last decades and therefore the heating load has fallen distinctly. That enables reduction of heat transfer areas or alternatively a decrease in the temperature of the heating medium. One of the systems suitable for low-temperature heating is floor heating. But the temperature of the floor surface is limited due to thermal comfort reasons. Another system is the use of classic radiators. Therefore, the heat transfer area must be much larger than in case of traditional convection radiators $[14,15]$. In this study, these two heating systems were analyzed. It is underfloor heating and heating with conventional radiators. We monitor their interaction and the effect on the resulting air temperature.

\section{Description of the analyzed model}

A zone with a floor area of $16.0 \mathrm{~m}^{2}$ and a volume of $42.4 \mathrm{~m}^{3}$ was selected for the given analysis. This is a zone that represents a standard residential room in a family house. For a given CFD simulation, two zones were modeled. One zone is considered to be heated with a transfer heating system in two alternatives. The first alternative is to transfer heat to the space by means of a wall radiator placed under a transparent structure, and the second alternative is underfloor heating built into the floor. The zone on the left is then unheated (Figs. 3 and 4). The mutual interaction between the individual zones is considered, which was also considered in

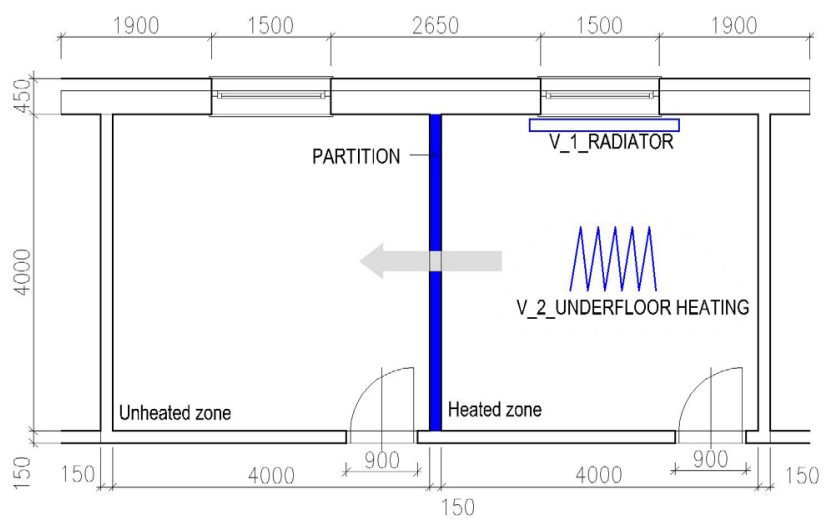

Fig. 3 Model geometry of individual simulated zones (heated and unheated zones) - Floor plan

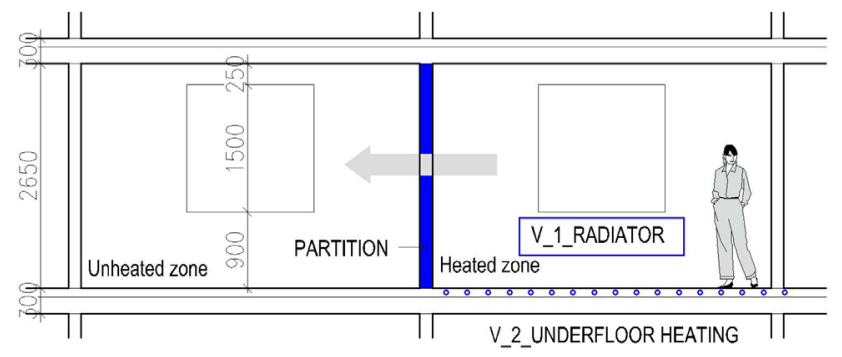

Fig. 4 Model geometry of individual simulated zones (heated and unheated zones) - Cross section 
the simulation. Individual envelope constructions (ceiling, perimeter wall, floor and transparent constructions) were designed from the thermal technical point of view so that they meet the criteria of recommended values which are set in the standard STN 73 0540-2:2012 [16].

\subsection{Thermal properties}

For the perimeter wall the value is $U_{\text {wall }}=0.22 \mathrm{~W} /\left(\mathrm{m}^{2} \mathrm{~K}\right)$, transparent structures are defined by the value $U_{\text {window }}=0.90 \mathrm{~W} /\left(\mathrm{m}^{2} \mathrm{~K}\right)$ (partial values for glazing $U_{\mathrm{g}}=0.60$ and for frame $\left.U_{\mathrm{f}}=1.00 \mathrm{~W} /\left(\mathrm{m}^{2} \mathrm{~K}\right)\right)$. In order to be able to analyze the interaction of the heated zone and the unheated zone, it is necessary to determine the thermal properties of the partition, non-load-bearing structure. For the analysis of the interaction of both zones, their thermal properties were considered in two alternatives. The first alternative is a partition hr. $150 \mathrm{~mm}$ with a coefficient of thermal conductivity $\lambda=0.13 \mathrm{~W} /(\mathrm{m} \mathrm{K})$, so we meet the requirements of the standard for the partition between flats $U_{\text {Partition }}=0.75 \mathrm{~W} /\left(\mathrm{m}^{2} \mathrm{~K}\right)$, - (in practice, this material occurs as a ceramic fired brick) and the second alternative is a partition $150 \mathrm{~mm}$ with $\lambda=1.58 \mathrm{~W} /(\mathrm{m} \mathrm{K})$ - (in practice this material occurs as a reinforced concrete structure).

\subsection{Description of individual variants}

For a given CFD simulation, two zones were modeled. One zone is heated with a heating system in two alternatives:

1. The first alternative is to transfer heat to the space by means of a wall radiator placed under a transparent structure and

2. the second alternative is underfloor heating, built into the floor.

The mutual interaction between the individual zones is considered, which was also considered in the simulation. The second zone is considered without heating. In addition to the change of the heating system, the thermal technical properties of the internal partition between the zones are changing.

\section{Calculation methodology}

The FLOVENT simulation program was used for the given analysis. FLOVENT [15] is a powerful fluid dynamics (CFD) software that predicts 3D airflows, heat transfer, optimization of heating, ventilation and air conditioning (HVAC) systems, and more. In our paper, the analysis of the impact of a heated zone with two alternatives of heat transfer, with two alternatives thermal technical properties of the non-load-bearing partition and with different intensity of air exchange to the unheated zone. This analysis is intended to confirm that heating in buildings cannot be properly regulated unless zone-based heating is used. The thermal technical requirements of the heat exchange package, the orientation of the transparent structures, the thermal and accumulation properties of the partitions between the individual zones, the user himself, the ventilation of the rooms, the heating system and especially the heat transfer to the room have a significant influence on zone heating. The air exchange intensity for the individual zones was determined successively with values of $n=0.10 ; 0.30$ and $0.501 / \mathrm{h}$.

\subsection{Simulation CFD analysis of the interaction of heated and unheated zones}

The simulation was carried out with the geometric, material and boundary conditions described above, exterior air temperature $-11.0{ }^{\circ} \mathrm{C}$, one perimeter wall, partitions, ceilings and a heating system ensuring thermal comfort of the space in the floor heating version with a system capacity of $28.0 \mathrm{~W} / \mathrm{m}^{2}$ (a total of $496.0 \mathrm{~W}$ ) and a wall radiator with a capacity of $375.0 \mathrm{~W}$. The energy requirement for infiltration $n=0.501 / \mathrm{h}$ is $127.0 \mathrm{~W}$ heat loss and $221.0 \mathrm{~W}$ ventilation, a total of about 348.0 W (see in Fig. 5).

\subsection{Results of the analyzed interaction of individual zones in the simulation}

Figs. 6-9 show cross-sections of both temperatures, both zones, with different combinations of the individual alternatives. Comprehensive results from all these combinations of heated and unheated zone solutions are shown in Table 1. Figs. 6 and 7 show the results of the distribution of air temperature and operating temperature. It is underfloor heating. The air exchange rate is set at $0.11 / \mathrm{h}$ and the partition changes. In the first case, partitions made of concrete and in the second one partitions made of ceramic brick are used. In the Figs. 8 and 9, the air exchange rate is $0.51 / \mathrm{h}$.

Figs. 10 and 11 show the results of the distribution of air temperature and operating temperature. It is heating radiator. The air exchange rate is set at $0.1 \mathrm{l} / \mathrm{h}$ and the partition changes. In the first case, partitions made of concrete and in the second one partitions made of ceramic brick are used. Figs. 12 and 13 show the results of the distribution of air temperature and operating temperature. It is heating radiator. The air exchange rate is set at $0.5 \mathrm{l} / \mathrm{h}$ and the partition changes. In the first case, partitions made of concrete and in 


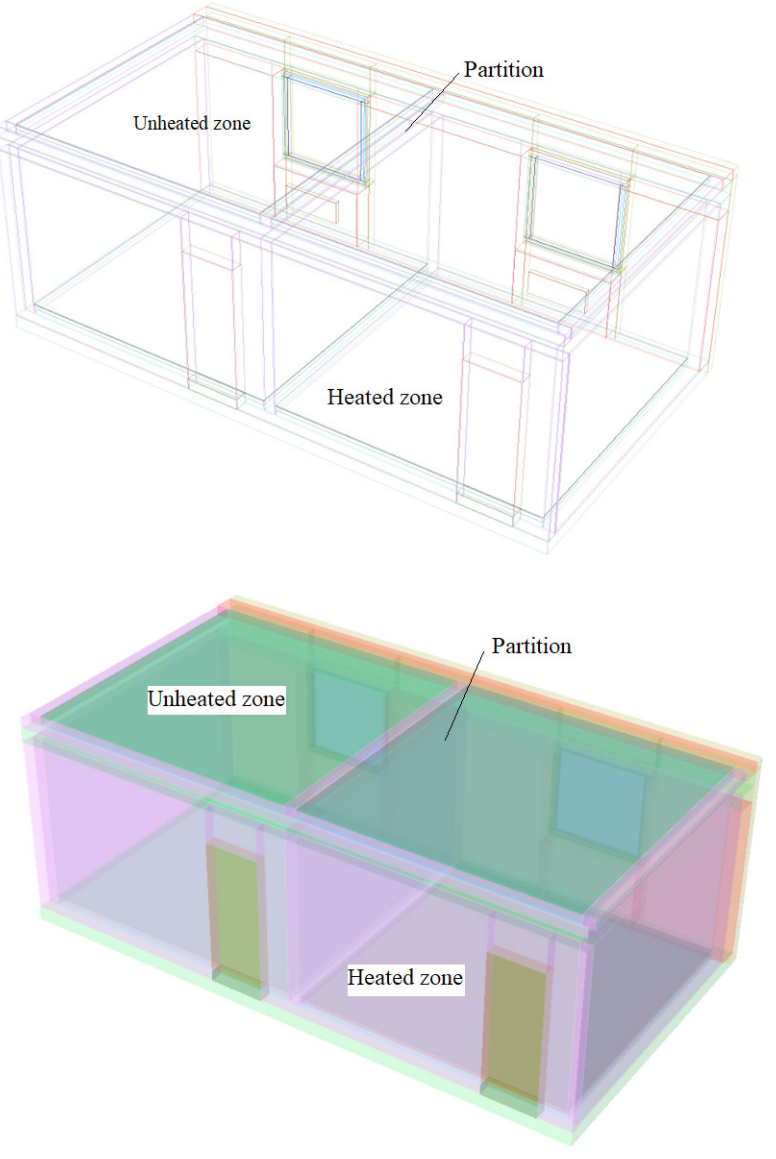

Fig. 5 Model of individual zones (heated and unheated) from the FLOVENT program
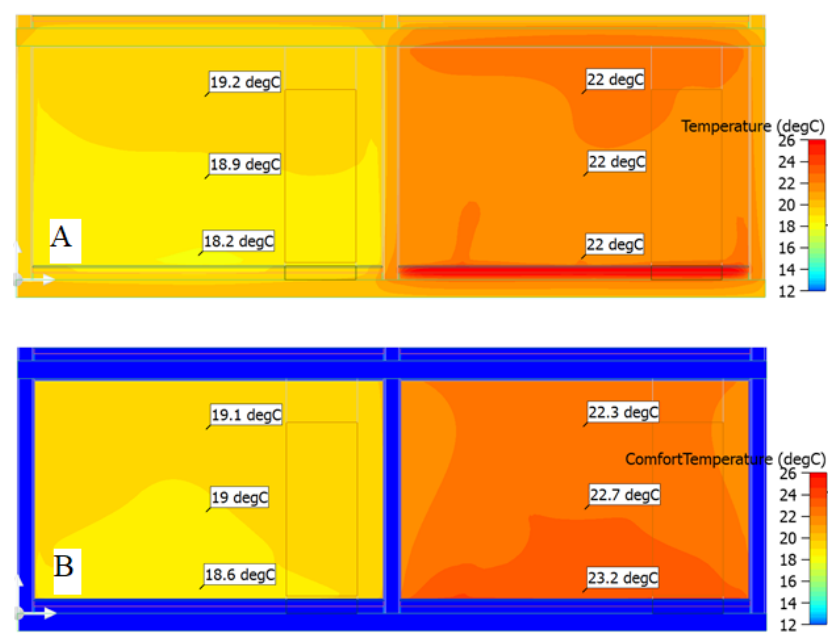

Fig. 6 Temperature display for underfloor heating with air exchange rate $n=0.101 / \mathrm{h}$ and the partition of the dividing zone is made of reinforced concrete $-\lambda=1.58 \mathrm{~W} /(\mathrm{m} \mathrm{K})$; A - Air temperature; $\mathrm{B}$ - Operating temperature

the second one partitions made of ceramic brick are used. The radiator is located in the heated zone under the window.

Tables 1 and 2 and Figs. 14 and 15 show the results from the average air temperature in individual zones for both heating variants.
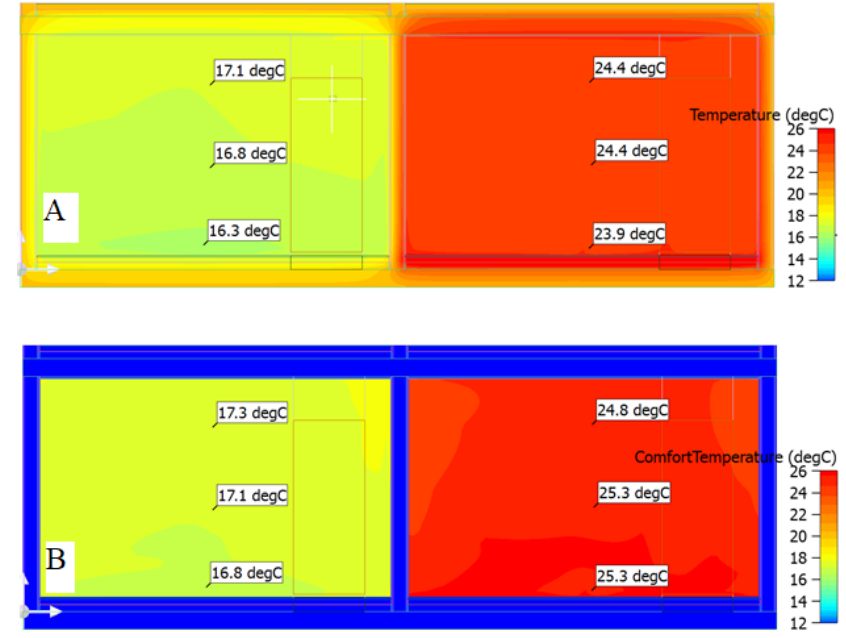

Fig. 7 Temperature display for underfloor heating with air exchange rate $n=0.101 / \mathrm{h}$ and the partition of the dividing zone is made of ceramic brick - $\lambda=0.13 \mathrm{~W} /(\mathrm{m} \mathrm{K})$; A - Air temperature; B - Operating temperature
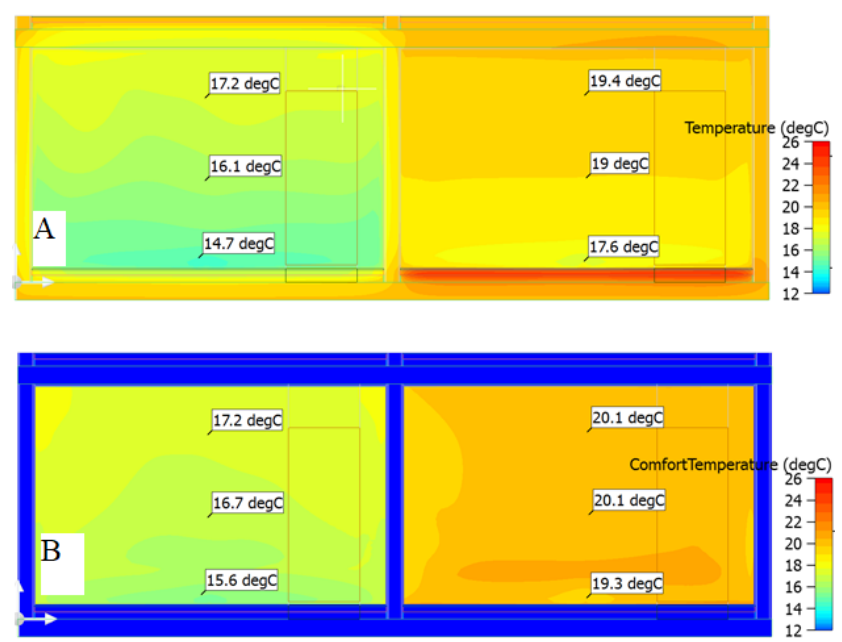

Fig. 8 Temperature display for underfloor heating with air exchange rate $n=0.51 / \mathrm{h}$ and the partition of the dividing zone is made of reinforced concrete $-\lambda=1.58 \mathrm{~W} /(\mathrm{m} \mathrm{K})$; A - Air temperature; $\mathrm{B}$ - Operating temperature
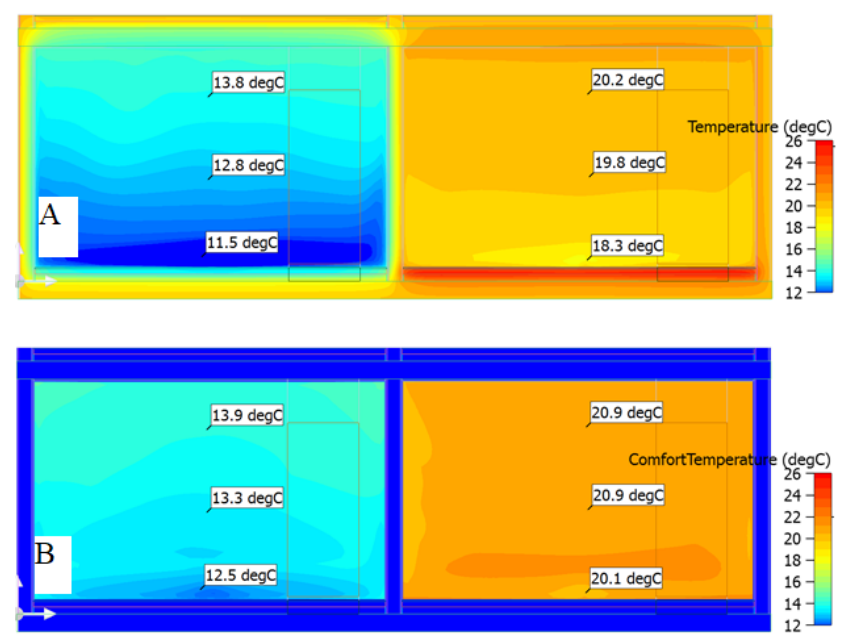

Fig. 9 Temperature display for underfloor heating with air exchange rate $n=0.51 / \mathrm{h}$ and the partition of the dividing zone is made of ceramic brick - $\lambda=0.13 \mathrm{~W} /(\mathrm{m} \mathrm{K})$; A - Air temperature; B - Operating temperature 

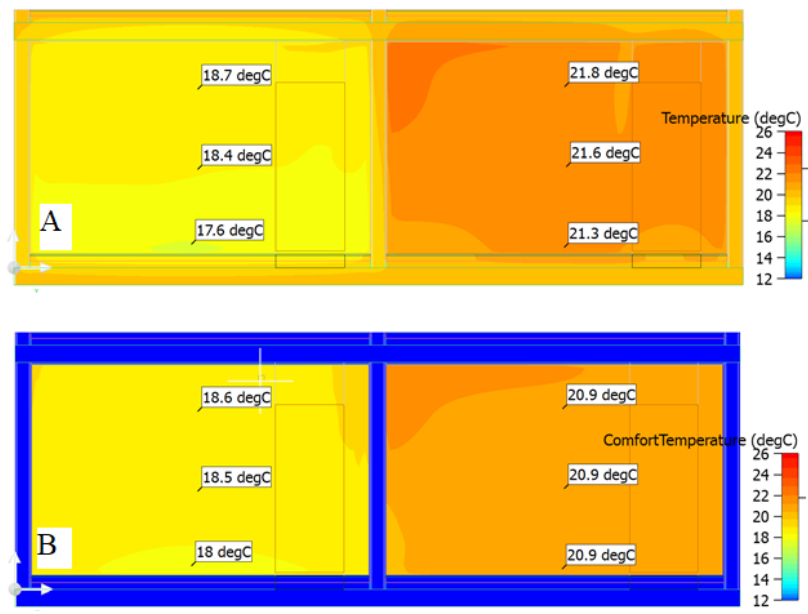

Fig. 10 Temperature display for heating radiator with air exchange rate $n=0.101 / \mathrm{h}$ and the partition of the dividing zone is made of reinforced concrete $-\lambda=1.58 \mathrm{~W} /(\mathrm{m} \mathrm{K})$; A - Air temperature; $\mathrm{B}$ - Operating temperature
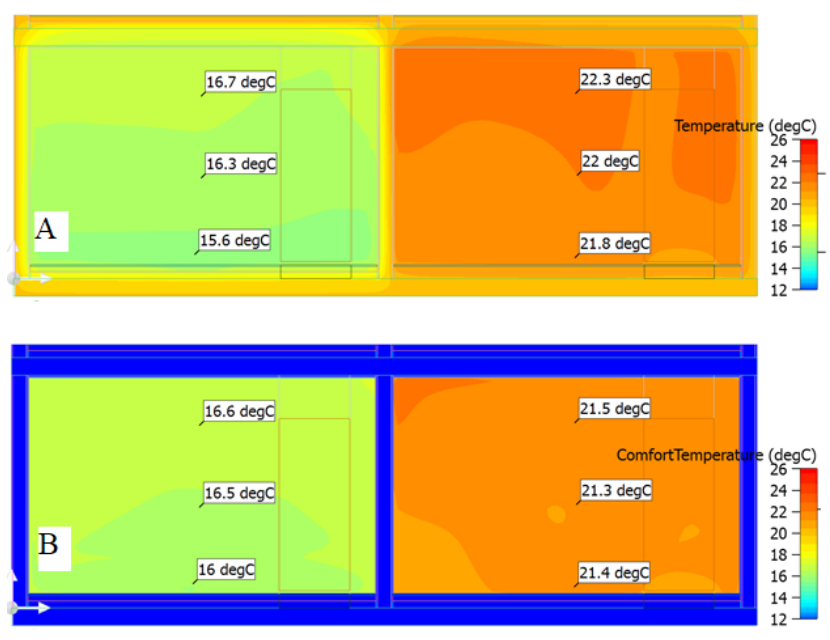

Fig. 11 Temperature display for heating radiator with air exchange rate $n=0.101 / \mathrm{h}$ and the partition of the dividing zone is made of ceramic brick - $\lambda=0.13 \mathrm{~W} /(\mathrm{m} \mathrm{K})$; A - Air temperature; B - Operating temperature
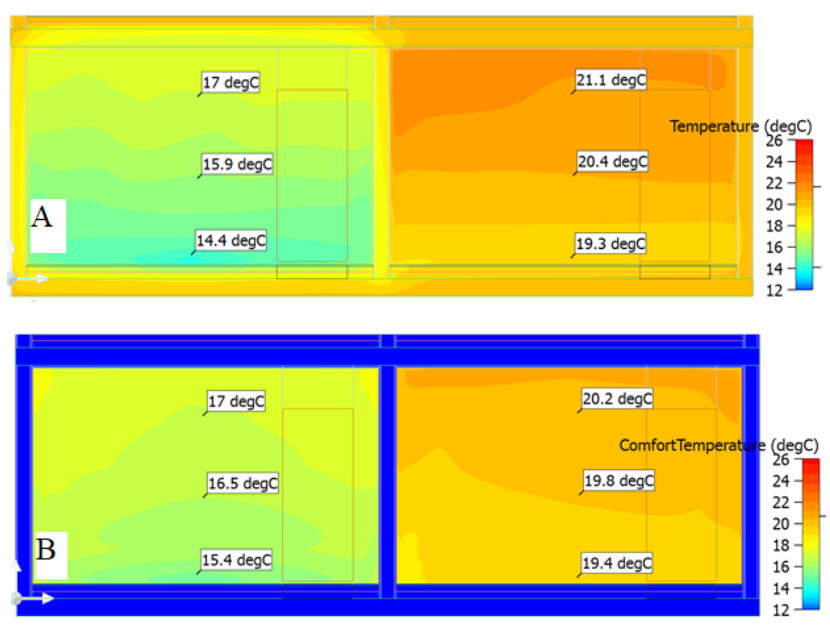

Fig. 12 Temperature display for heating radiator with air exchange rate $n=0.501 / \mathrm{h}$ and the partition of the dividing zone is made of reinforced concrete $-\lambda=1.58 \mathrm{~W} /(\mathrm{m} \mathrm{K})$; A - Air temperature; $\mathrm{B}$ - Operating temperature
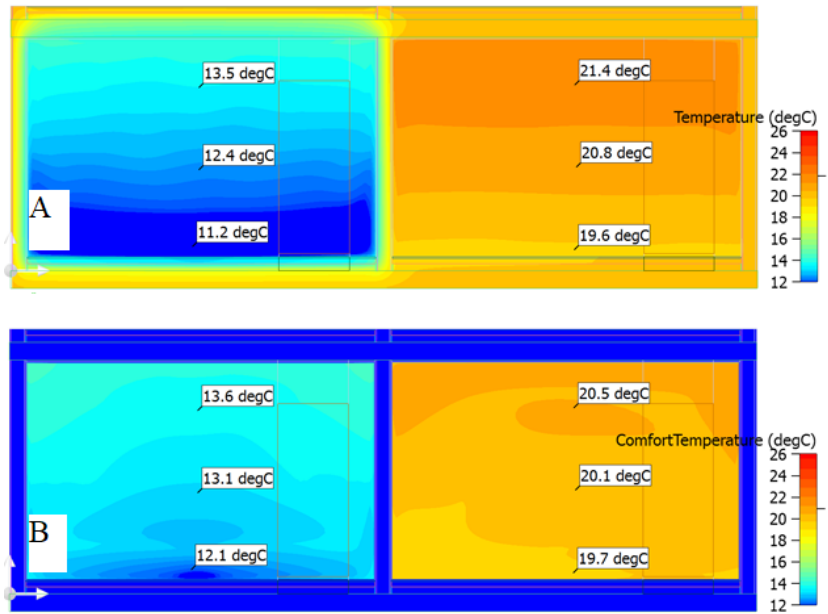

Fig. 13 Temperature display for heating radiator with air exchange rate $n=0.501 / \mathrm{h}$ and the partition of the dividing zone is made of ceramic brick - $\lambda=0.13 \mathrm{~W} /(\mathrm{m} \mathrm{K})$; A - Air temperature; B - Operating temperature

Figs. 16 and 17 show the airflow for both analyzed variants.

\section{Discussion}

Temperature control according to one building thermostat is inefficient in net zero energy buildings. Zone temperature control must be designed to achieve low energy consumption. Such a system can dynamically regulate the heat source and thus save energy. One of the control systems is intelligent control according to the set temperature, humidity, or $\mathrm{CO}_{2}$ concentration. Zone management also provides benefits during a COVID pandemic. Everything is controlled centrally and without touch. Therefore, we recommend designing buildings with net zero energy demand as intelligent buildings. Experiments are currently underway on the problem of zone temperature control. Based on the experiment, verifications and results will be published. The simulation results confirm that zone control is required.

\section{Conclusion}

As can be seen from the previous results, zone heating has a significant effect on the temperatures in the zones. The presented results prove that if two rooms were placed next to each other, one of which is heated and the other is not, the unheated one would be significantly subcooled with a decrease in operating temperature of up to about $3.3 \mathrm{~K}$ for concrete and even up to $7.5 \mathrm{~K}$ at the brick partition, against the heated room. The simulations have also shown that underfloor heating decreases the air temperature in the version of the reinforced concrete partition by $2.1 \mathrm{~K}$ and in the case of bricks by up to $4.6 \mathrm{~K}$ as the 
Table 1 Average air temperature in the zone

\begin{tabular}{|c|c|c|c|c|c|c|c|}
\hline \multirow{4}{*}{ 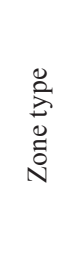 } & \multirow{4}{*}{ Heating system } & \multicolumn{6}{|c|}{ Average air temperature in the zone $\left({ }^{\circ} \mathrm{C}\right)$} \\
\hline & & \multicolumn{3}{|c|}{ Partition - $150 \mathrm{~mm}$ brick } & \multicolumn{3}{|c|}{ Partition - $150 \mathrm{~mm}$ concrete } \\
\hline & & \multicolumn{3}{|c|}{ air exchange rate $(1 / \mathrm{h})$} & \multicolumn{3}{|c|}{ air exchange rate $(1 / \mathrm{h})$} \\
\hline & & $n=0.10$ & $n=0.30$ & $n=0.50$ & $n=0.10$ & $n=0.30$ & $n=0.50$ \\
\hline \multirow{2}{*}{ 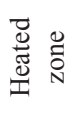 } & Underfloor heating (power $28.0 \mathrm{~W} / \mathrm{m}^{2}$ ) & 24.33 & 22.09 & 19.72 & 21.98 & 20.39 & 18.91 \\
\hline & Radiator (power $375.0 \mathrm{~W}$ ) & 21.91 & 21.62 & 20.72 & 21.52 & 21.38 & 20.39 \\
\hline \multirow{2}{*}{ 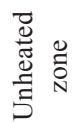 } & Underfloor heating (power $28.0 \mathrm{~W} / \mathrm{m}^{2}$ ) & 16.91 & 14.80 & 12.81 & 18.86 & 17.19 & 16.08 \\
\hline & Radiator (power $375.0 \mathrm{~W}$ ) & 16.26 & 14.29 & 12.53 & 18.32 & 16.99 & 15.93 \\
\hline
\end{tabular}

Table 2 Average operating temperature in the zone

\begin{tabular}{|c|c|c|c|c|c|c|c|}
\hline \multirow{4}{*}{ 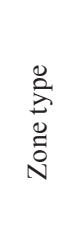 } & \multirow{4}{*}{ Heating system } & \multicolumn{6}{|c|}{ Average operating temperature in the zone $\left({ }^{\circ} \mathrm{C}\right)$} \\
\hline & & \multicolumn{3}{|c|}{ Partition - $150 \mathrm{~mm}$ brick } & \multicolumn{3}{|c|}{ Partition - $150 \mathrm{~mm}$ concrete } \\
\hline & & \multicolumn{3}{|c|}{ air exchange rate $(1 / \mathrm{h})$} & \multicolumn{3}{|c|}{ air exchange rate $(1 / \mathrm{h})$} \\
\hline & & $n=0.10$ & $n=0.30$ & $n=0.50$ & $n=0.10$ & $n=0.30$ & $n=0.50$ \\
\hline \multirow{2}{*}{ 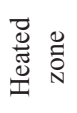 } & Underfloor heating (power $28.0 \mathrm{~W} / \mathrm{m}^{2}$ ) & 24.89 & 22.84 & 21.95 & 22.35 & 21.10 & 19.91 \\
\hline & Radiator (power $375.0 \mathrm{~W}$ ) & 21.36 & 21.00 & 20.03 & 20.88 & 20.61 & 19.74 \\
\hline \multirow{2}{*}{ 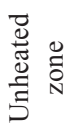 } & Underfloor heating ( power $28.0 \mathrm{~W} / \mathrm{m}^{2}$ ) & 17.21 & 15.26 & 14.67 & 19.03 & 17.81 & 16.84 \\
\hline & Radiator power $375.0 \mathrm{~W}$ ) & 16.51 & 14.80 & 13.25 & 18.57 & 17.62 & 16.71 \\
\hline
\end{tabular}

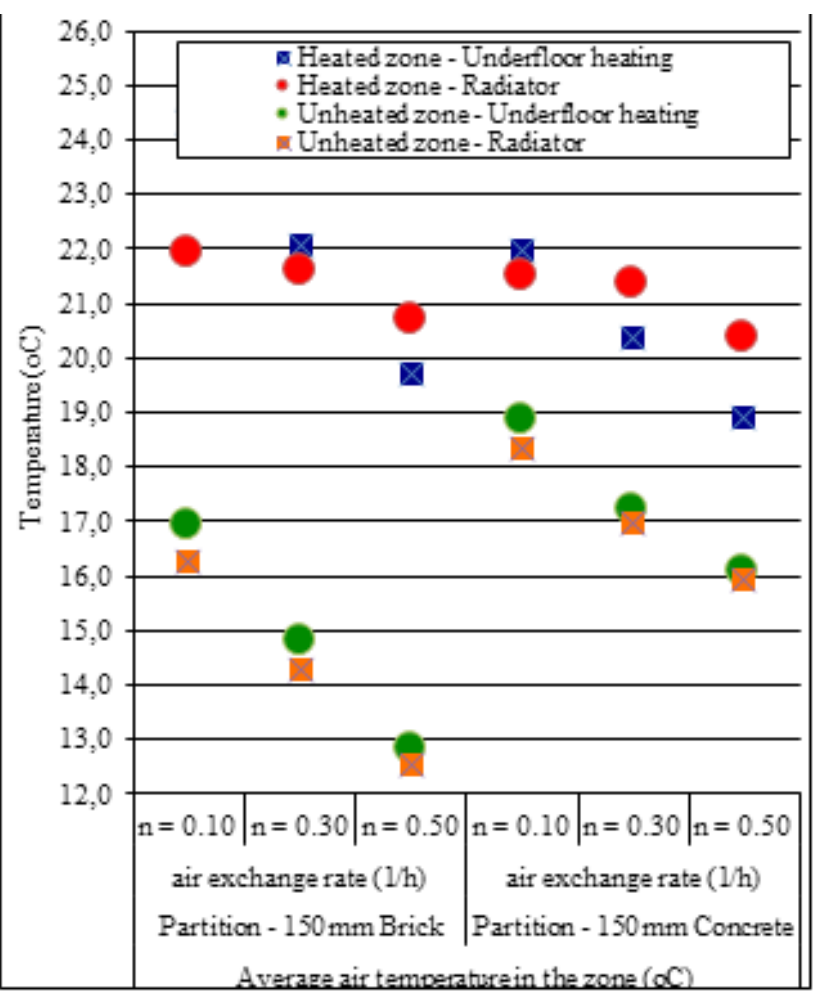

Fig. 14 Results of the analyzed interaction of individual zones in the simulation

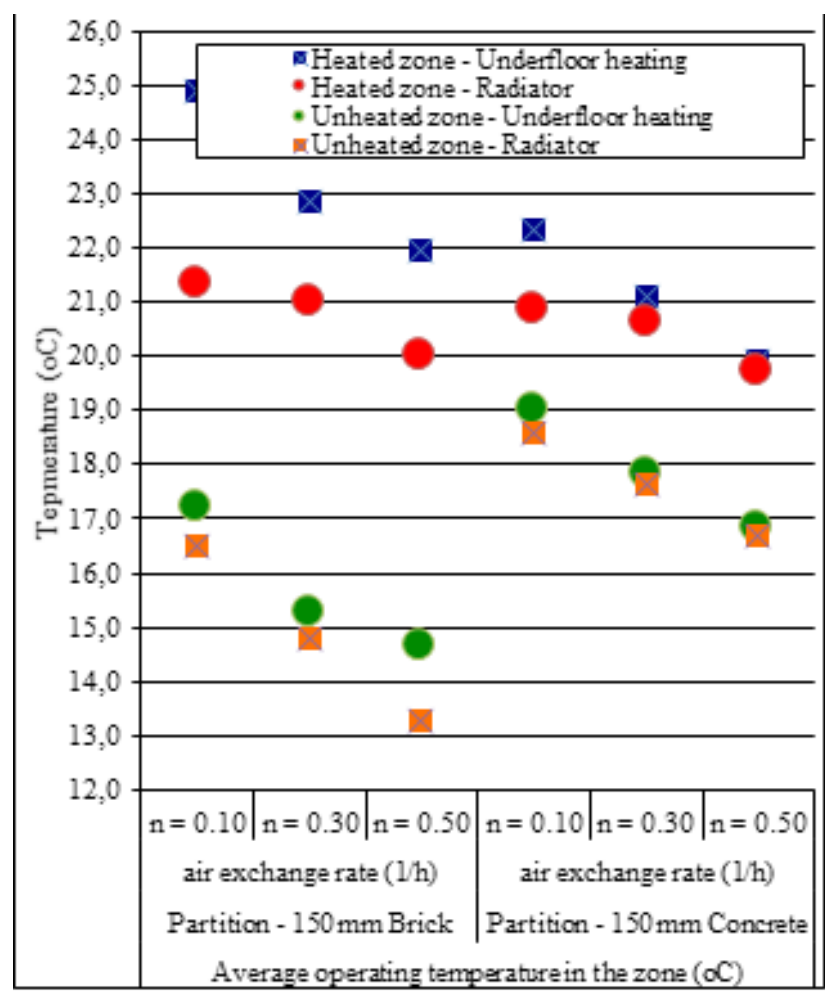

Fig. 15 Results of the analyzed interaction of individual zones in the simulation 

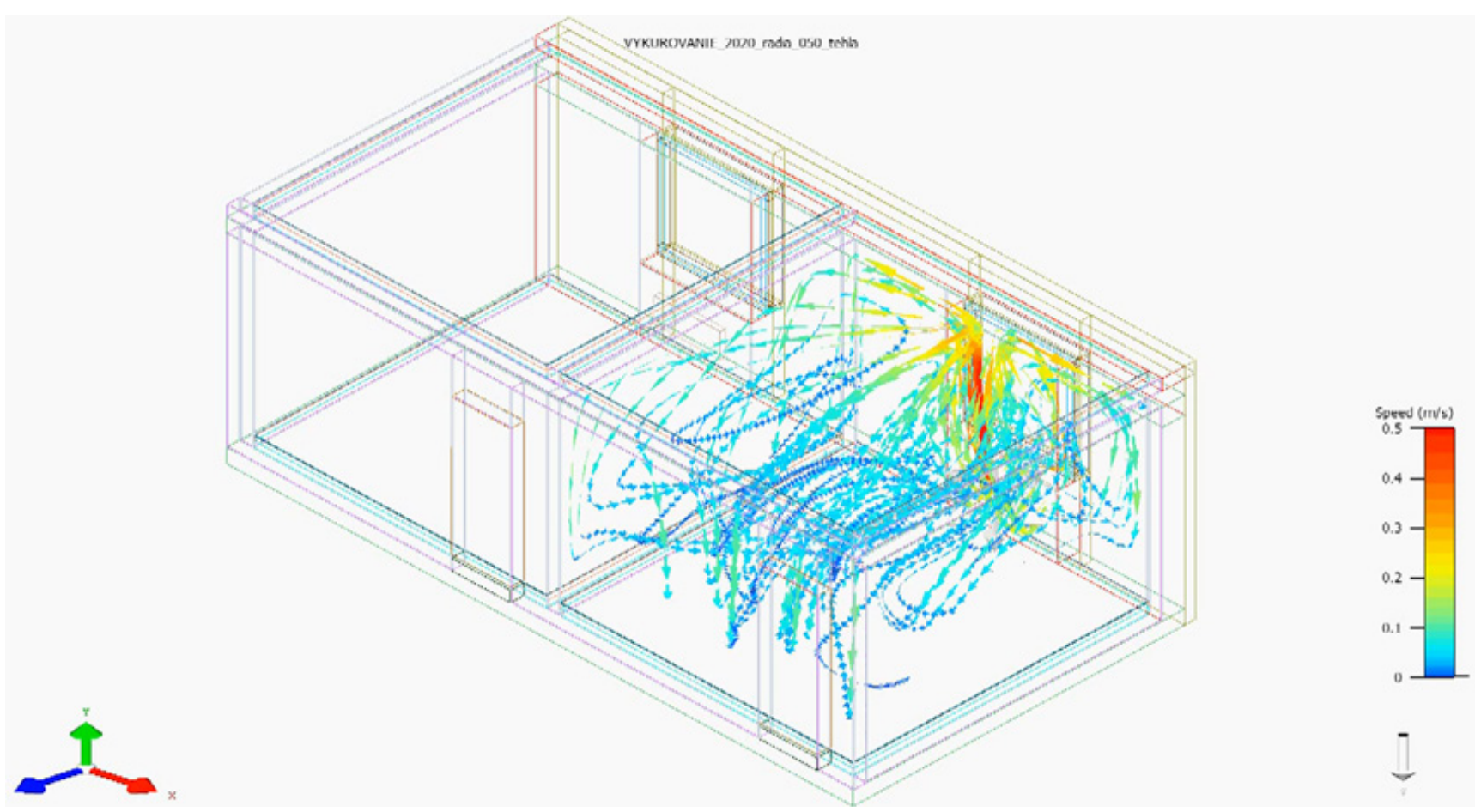

Fig. 16 Air flow - radiator
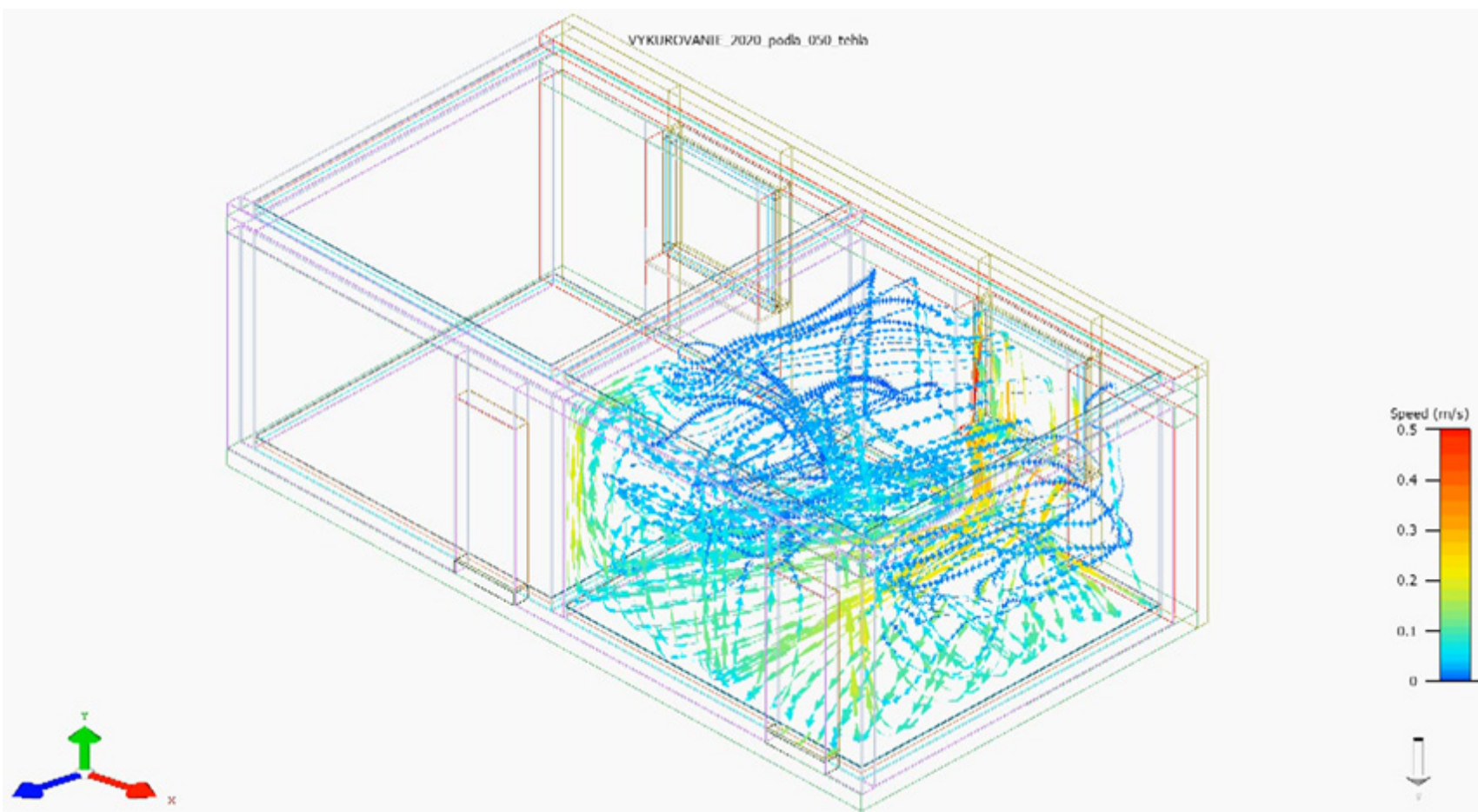

Fig. 17 Air flow - underfloor heating

infiltration increases (from 0.10 to $0.501 / \mathrm{h}$ ). If there was a thermostat in only one of the rooms, it would lead to significant discomfort. From the point of view of the efficiency of the whole heating system, it turns out that the radiator is more suitable, because for example when exchanging air $n=0.501 / \mathrm{h}$ it requires an energy capacity of $375.0 \mathrm{~W}$ to maintain the identical air temperature of $+20.72{ }^{\circ} \mathrm{C}$ (while the underfloor heating "requires" $496.0 \mathrm{~W})$. It is necessary to design smart solutions not only for the heating system but for the entire building. This is necessary in this COVID-19 pandemic. Everything is controlled by the system itself without touching individual devices. 


\section{Acknowledgement}

The project presented in this article is supported by the VEGA-1/0229/21.

\section{References}

[1] Act no. 300/2012. "Amending and supplementing Act no. 555/2005 on the energy performance of buildings and on amendments to certain acts, as amended, and amending and supplementing Act no. 50/1976 on land-use planning and building code (Building Act), as amended", Bratislava, Slovakia, 2012.

[2] Ingeli, R., Čekon, M. "Analysis of Energy Consumption in Building with NZEB Concept", Applied Mechanics and Materials, 824, pp. 347-354, 2016.

https://doi.org/10.4028/www.scientific.net/AMM.824.347

[3] Ingeli, R. "Analysis of alternative energy sources in Building with NZEB Concept", In: Advanced Building Construction and Materials 2016 (ABCM 2016), Luhačovice, Czech Republic, 2016, pp. 347-354.

[4] Buckman, A. H., Mayfield, M., Beck, S. B. M. "What is a Smart Building?", Smart Sustainainable Built Environment, 3(2), pp. 92-109, 2014.

https://doi.org/10.1108/SASBE-01-2014-0003

[5] Clements-Croome, D. J. "Sustainable healthy intelligent buildings for people", In: Intelligent Buildings: Design, management and operation,Thomas Telford Ltd., London, UK, 2013, pp. 1-24. https://doi.org/10.1680/ib.57340.001

[6] Hartkopf, V., Loftness, V., Mahdavi, A., Lee, S., Shankavaram, J. "An integrated approach to design and engineering of intelligent buildings - The Intelligent Workplace at Carnegie Mellon University", Automation in Construction, 6(5-6), pp. 401-415, 1997. https://doi.org/10.1016/S0926-5805(97)00019-8

[7] Omar, O. "Intelligent building, definitions, factors and evaluation criteria of selection", Alexandria Engineering Journal, 57(4), pp. 2903-2910, 2018 .

https://doi.org/10.1016/j.aej.2018.07.004

[8] Wong, J. K. W., Li, H., Wang, S. W. "Intelligent building research: a review", Automation in Construction, 14(1), pp. 143-159, 2005. https://doi.org/10.1016/j.autcon.2004.06.001

[9] Azevedo Guedes, A. L., Carvalho Alvarenga, J., Dos Santos Sgarbi Goulart, M., Rodriguez y Rodriguez, M. V., Pereira Soares, C. A. "Smart Cities: The Main Drivers for Increasing the Intelligence of Cities", Sustainability, 10(9), Article number: 3121, 2018. https://doi.org/10.3390/su10093121
[10] Joustra, C., Yeh, D. H. "Decision support systems for water reuse in smart building water cycle management", In: Memon, F. A., Ward, S. (eds.) Alternative Water Supply Systems, IWA Publishing, London, UK, 2014, pp. 393-420. https://doi.org/10.2166/9781780405513

[11] Lima, E. G., Chinelli, C. K., Guedes, A. L. A., Vazquez, E. G., Hammad, A. W. A., Haddad, A. N., Pereira Soares, C. A. "Smart and Sustainable Cities: The Main Guidelines of City Statute for Increasing the Intelligence of Brazilian Cities", Sustainability, 12(3), Article number: 1025, 2020. https://doi.org/10.3390/su12031025

[12] McGlinn, K., O'Neill, E., Gibney, A., O'Sullivan, D., Lewis, D. "SimCon: A Tool to Support Rapid Evaluation of Smart Building Application Design using Context Simulation and Virtual Reality", Journal of Universal Computer Science, 16(15), pp. 1992-2018, 2010 . https://doi.org/10.3217/jucs-016-15-1992

[13] Glasmeier, A., Christopherson, S. "Thinking about smart cities", Cambridge Journal of Regions, Economy and Society, 8(1), pp. 3-12, 2015. https://oi.org/10.1093/cjres/rsu034

[14] Strzeszewski, M. "Zasięg cieplny pojedynczego liniowego źródła ciepła w stropie na podstawie modelu numerycznego" (Thermal range of a single linear heat source in the ceiling on the basis of the numerical model), In: 13th Conference of Heating Engineers, Solina, Poland, 2001, pp. 331-339. (in Polish)

[15] FloVENT® 10.1 "Optimize HVAC airflows with fast, easy-touse and industry-proven CFD simulation", [online] Available at: www.mentor.com/https://www.mentor.com/products/mechanical/ flovent/ [Accessed: 07 December 2019]

[16] Slovak Republic "STN 73 0540-2:2012 Thermal protection of buildings. Thermal performance of buildings and components. Part 2: Functional requirements", Slovak Standards Institute, Bratislava, Slovakia, 2012. 